\title{
Massive haematuria with clot retention: management options
}

\author{
Aravinthan Thevarajah MBBS MD MRCS Ed
}

Senior Registrar in Urology, Teaching hospital Kandy.

Key words: Bladder tamponade; Massive haematuria; Renal cell carcinoma.

\section{Introduction}

Accumulation of blood clot following urological procedure (bladder tamponade ) and massive haematuria is a troublesome situation to the clinician. The uncontrolled haematuria may be due to a malignancy such as renal cell carcinoma and carcinoma of the bladder or due to benign conditions such as benign prostatic hyperplasia, and various types of cystitis. This review aims to summarise the evidence based practice in this common clinical entity and discuss the guidelines to manage uncontrolled haematuria and clot retention.

\section{Evidence based approach}

Patients can present with intractable haematuria or symptoms of clot retention such as supra pubic pain, difficulty in passing urine. Massive clot retention can over distend the bladder and lead to urine outflow obstruction.

Clot retention and intractable haematuria can increase the patient's morbidity following urological procedures and reported incidence of clot retention is $2.5 \%-10 \%$ following TURP [1,2]. Patient should be evaluated in a conventional way such as history and examination to find out the possible aetiology.

\section{Bladder irrigation}

After the initial resuscitation a three way large bore urinary catheter, possibly 22 Fr foley catheter should be inserted under sterile conditions and immediate bladder irrigation should be started. Normal saline irrigation is better than water irrigation and the irrigation fluids dislodge the clot from the bladder and facilitates clot clearance [3]. There is no standard amount of irrigation fluids but it should be decided on an individual basis and irrigation should be continued until the effluent becomes clear.

Water is not recommended as an irrigation fluid because it can be absorbed via the process of osmosis from the bladder and can cause dilution of electrolytes in the circulatory system.

In some situations the clot can dislodge and obstruct the irrigating catheter lumen and patient will develop supra pubic pain with distended bladder. Irrigation should be stopped immediately and bladder washout should be done without

Correspondence: Aravinthan Thevarajah

Senior Registrar in Urology,Teaching Hospital Kandy. delay. Squeezing the catheter with a milking manoeuvre may be helpful to dislodge the clot.

\section{Bladder washout}

This should be done under sterile conditions because bladder irrigation can cause urinary tract infection. Instillation of fluids in to the bladder using a bladder syringe will dislodge the clot and debris and forceful suction bring the clots out of the system. This is a very common and effective procedure to manage postoperative clot retention. However, the clinician should be aware about the risk of urinary tract infection.

\section{Use of Tranexamic acid}

Tranexamic acid is an anti-fibrinolytic agent which inhibits the conversion of plasminogen to plasmin. It facilitates the formation of clot and helps to minimise the bleeding. There are some randomised control trials which support the use of Tranexamic acid during prostate surgery to minimise post operative bleeding [4]. But using Tranexamic acid in the bladder, pleural and abdominal cavity is not recommended due to the risk of formation of extra vascular clot which is highly resistant to physiological fibrinolysis.

\section{Cystoscopy and clot evacuation}

This should be reserved for resistant cases where the initial management fails to remove clots. This procedure should be done under general anaesthesia and clot can be sucked out using bladder syringe and some cases using the Ellik bladder evacuator. Some organised clots are highly resistant to evacuation and difficult to suck out and this situation can be managed by using the resectoscope to break the clot into small pieces by using cutting elements. Using intra-vesical instillation of streptokinase and hydrogen peroxide are not well studied in the current literature and not practiced in general.

\section{Specific options to control bleeding}

\section{1 \% Aluminium ammonium sulphate (Alum solution)}

There is enough evidence in the current English literature to support the use of Alum solution to control intractable haematuria due to bladder carcinoma and any form of cystitis. Success rate is $75 \%$ to $100 \%$ with few side effects and there is no reported lethal side effect [5-7].

The main action of alum solution is to precipitate the proteins around the bleeding surfaces and through it decrease the capillary permeability. The amount of solution and duration of infusion should be decided according to the clinical situation. The inventor of Alum solution Ostroff and Chenault, pro- 
posed at least $30 \mathrm{~L}$ of solution to be used to irrigate the bladder in 24 hours to achieve a favourable outcome [8].

\section{Formaline solution}

Intravesical formalin infusion causes protein precipitation around the leaking vessels and reduces the capillary permeability. A $10 \%$ formalin solution has a success rate of more than $90 \%$ in most case series but the reported side effects include contracted bladder, vesico ureteric reflux, urinary incontinence, and rupture of the bladder $[9,10]$.

The $10 \%$ formalin solution can be instilled under regional anaesthesia, and the maximum volume $300 \mathrm{ml}$ and the contact time should be less than 30 minutes. Concentration of formalin solution may vary from $1 \%$ to $10 \%$ among individuals but serious consequences should be taken in to account when considering the higher concentration.

\section{Hyperbaric oxygen therapy}

The background pathophysiology of radiation induced cystitis is a marked cellular hypoxia which can cause extensive cellular damage and massive haematuria. Hyperbaric oxygen therapy has some clinical advantage. $100 \%$ oxygen should be inhaled under three bar pressure at least for 90 minutes. Success rate depends on repeated cycles of therapy and reported success rate is more than $80 \%$ with minimum side effects [11].

\section{Irrigation with silver nitrate}

$1 \%$ of silver nitrate bladder washout leads to coagulation of vascular bed and control of the bleeding. It should be instilled for at least 20 minutes to obtain results.

\section{Therapeutic embolisation}

Embolisation of the internal iliac artery achieves haemostasis in severe haematuria following radiation cystitis. It can be done as an open procedure or through interventional radiology. Reported side effects are severe gluteal pain, distal embolisation and bladder gangrene.

\section{Bladder tamponade}

Increasing the hydrostatic pressure inside the bladder above the systolic pressure to control the bleeding was introduced by Helmstien in 1973 [12]. This procedure can be done under regional anaesthesia and the pressure should be maintained for at least 6-7 hours. Significant side effects include partial or complete rupture of the bladder.

\section{Intravesical carboprost tromethamine instillation}

Instillation of intravesical prostaglandin F2 alpha have varied results. Around 1mg/dl of PGF2 should be used for two hours at least four times per day. Side effects eg. painful bladder spasms, are minimal.

\section{Other treatment modalities}

Surgical options such as palliative cystectomy and urinary diversion may be useful in uncontrolled haematuria where all the above bladder sparing measures fail. Chemoradiation to the bladder is also practiced in some centres with variable results.

\section{Conclusion}

Intractable haematuria is a troublesome clinical situation for clinicians and should be dealt with a multimodal treatment plan. Using an evidence based approach, intractable haematuria can be managed with a high success rate. Patients' general condition, comorbidity and probable aetiology for uncontrolled bleeding should be considered when deciding treatment.

\section{References}

1. Mebust WK, Holtgrewe HL, Cockett ATL et al. Transurethral prostatectomy: immediate and postoperative complications. A cooperative study of 13 participating institutions evaluating 3,885 patients. J Urol 1989; 141: 2437

2. Harvey MH, Leese T, Lloyd D, Osborn DE Antibiotic prophylaxis and secondary haemorrhage following transurethral resection of the prostate: a prospective trial. Br J Urol 1986; 58: 4502

3. Ann E,Daniel Painter et al. Blocked urinary catheters: nurses' preventive role.2001;97:37-38

4. Rannikko A, Petas A, Taari K. Tranexamic acid in control of primary hemorrhage during transurethral prostatectomy. Urology 2004;64:955-8

5. Arrizabalaga M, Extramiana J, Parra JL, Ramos C, Diaz Gonzalez R, Leiva O. Treatment of massive haematuria with aluminous salts. Br J Urol 1987; 60: 223 \pm 6

6. Goel AK, Rao MS, Bhagwat AG, Vaidyanathan S, Goswami AK, Sen TK. Intravesical irrigation with alum for the control of massive bladder haemorrhage. J Urol. 1985;133:956-957.

7. Arrizabalaga M, Extramiana J, Parra JL, Ramos C, Diaz Gonzalez R, Leiva O. Treatment of massive haematuria with aluminium salts. Br J Urol. 1987;60:223-226.

8. Ostroff EB, Chenault OW Jr. Alum irrigation for the control of massive bladder hemorrhage. J Urol 1982; 128: 929 \pm 30

9. Brown RB. A method of management of inoperable carcinoma of the bladder. Med J Aust 1969; 1: 23

10. Godec CJ, Gleich P. Intractable hematuria and formalin. J Urol 1983; 130: 688 \pm 91

11. Bevers RF, Bakker DJ, Kurth KH. Hyperbaric oxygen treatment for haemorrhagic radiation cystitis. Lancet. 1995;346:803-5.

12. Helmstein K. Treatment of bladder carcinoma by a hydrostatic pressure technique. Br J Urol 1972; 44: 434 \pm 50

13. Chan RC, Bracken RB, Johnson DE. Single dose whole pelvis megavoltage irradiation for palliative control of hematuria or ureteral obstruction. J Urol. 1979;122:750-1. 